\title{
ESPIRITUALIDAD FEMENINA E ISLAM: LA VOZ DEL SILENCIO
}

\author{
MONTSERRAT ABUMALHAN MAS \\ Universidad Complutense Madrid
}

Recibido: 15/07/2012

Aceptado: 08/10/2012

\section{Resumen}

La espiritualidad femenina es abordada como una expresión profunda y significativa de la fe musulmana. Las mujeres, sin embargo, aparecen raramente en los testimonios históricos, aunque aquellas de las que tenemos noticia fueron maestras en su entrega al amor divino.

Palabras clave: espiritualidad, femenina, islam, testimonios

\begin{abstract}
Feminine spirituality is addressed as a deep and meaningful expression of the Murslim faith. Women, however, rarely appear in the historical records, but those which we know about were teachers in their commitment to divine love.
\end{abstract}

Keyword: spirituality, feminine, murslim, historical records 

La vida espiritual es esencial en toda experiencia religiosa. Sin embargo, existen diversos modos de comprensión de la misma, así como muy diversas maneras de expresar la vivencia espiritual, que no es otra cosa que la relación que se establece entre el Misterio o lo Absoluto y el ser humano.

El islam como gran religión revelada ha escogido una de las posibles vías de manifestación de la experiencia religiosa. En este sentido, en relación con las otras tres religiones monoteístas, se halla quizá más cerca de la visión que el judaísmo posee de la vida espiritual, que del cristianismo.

Como es sabido, en el judaísmo la Ley (Torah) es el centro de la vida espiritual. Sus desarrollos (Mishna y Talmud), su conocimiento y la práctica de sus preceptos constituyen el modo a través del cual el creyente judío se acerca a Dios. Este cumplimiento no sólo aparece como una forma de relación del hombre con la divinidad, sino que es también el modo en que Dios se revela y manifiesta su voluntad ${ }^{1}$.

De manera muy semejante en el islam, el cumplimiento de los preceptos es la forma en que el creyente hace expresión de su sumisión a la voluntad divina, su aceptación de la propia existencia de Dios y el modo de dar a Dios aquello que Él recomienda y pide a los seres humanos.

Los preceptos básicos del Islam; peregrinación, oración, ayuno y limosna, con las condiciones, restricciones y ampliaciones que los doctores de la ley han ido precisando a lo largo de la historia de esta religión, son la base de la espiritualidad musulmana.

Este carácter ritualizado del desarrollo de la vida espiritual, que conlleva así mismo una cierta rigidez, ha sido causa de contestación por parte de numerosas personalidades a lo largo del tiempo, así como el motivo, junto con otros, de que surgieran tanto la vida ascética, como la vía mística en el seno del islam.

El islam se caracteriza por una comprensión cerrada de la Unicidad de Dios. Su monoteísmo no admite personas ni naturalezas en la divinidad. La consideración de que Dios es lo Todo Otro, que posee una naturaleza diferente de la del hombre así como el rechazo a la posibilidad de encarnación,

1. Luis Girón, El Talmud, Ed. Del Orto, Madrid, 2006.

Feminismo/s 20, diciembre 2012, pp. 259-273 
hicieron del dios concebido por el islam un ser lejano y cada vez más distante e incomprensible ${ }^{2}$.

Sus designios y voluntad empezaban a resultar para los creyentes, impulsados por las enseñanzas de teólogos temerosos de un retorno al politeísmo o al paganismo, cada vez más difíciles de desentrañar y alejados del entendimiento humano, incluso llegando a lo irracional, pues al hombre resultaba del todo imposible alcanzar las razones profundas de la voluntad divina. De ahí que el único modo de acercamiento y de relación de intimidad se redujera, para muchos creyentes, al estricto cumplimiento de los preceptos básicos, a los que se fueron añadiendo otras devociones ${ }^{3} \mathrm{y}$ mediaciones.

Sin embargo, como ya se ha dicho, a esta rigidez en el trato con la divinidad escapan espíritus libres y apasionados que, maravillados por la magnificencia de Dios, por su sabiduría, poder, amor y misericordia, aquello a lo que aspiran es a una relación más estrecha con ese ser. No hay que olvidar que uno de los atributos más repetido de Dios en el islam es el de la Suma Misericordia. Esa relación íntima se va descubriendo y manifestando como una experiencia de amor apasionado, que busca el apartamiento de cualquier distracción mundana y la unión con el Amado.

Desde los tiempos iniciales del islam hallamos personajes de este tipo que optan por la vida ascética; una vida de privaciones y pobreza, de constante oración que se acerca al ensimismamiento y de despego por todo aquello que no sea Dios.

Esta corriente de vida ascética y de búsqueda de una relación amorosa con Dios, derivará en una vía mística, el sufismo ${ }^{4}$, de inmenso calado y poblada de figuras señeras, que, no solo han dado a la vida espiritual y a la teología muchas aportaciones de gran riqueza y hondura, sino que han ampliado la inmensa producción poética de las distintas literaturas cultivadas en territorios musulmanes, especialmente en las literaturas árabe y persa.

No se trata en este lugar de desentrañar con detalle las causas u orígenes profundos de la mística en el islam o si tiene más o menos conexiones con los desarrollos aparentemente semejantes que se dan en otros ámbitos religiosos, tanto dentro del monoteísmo como fuera de él, aún cuando no esté de más

2. M. Abumalham, «Monoteísmo musulmán, diálogo y mediación», 'Ilu Revista de Ciencias de las Religiones, vol. 9, 2004, pp. 5-12.

3. Cristina de la Puente, «La oración», en M. Abumalham, Textos de la religiosidad musulmana, ed. Trotta, Madrid, 2005.

4. G.C. Anawati y L. Gardet, Mystique musulmane. Aspects et tendences, expériences et techniques, Paris, 1961; A.J. Arberry, An Introduction to the History of Sufism, London, 1942; Le Soufisme, Paris, 1988. 
señalar que la mística musulmana posee una personalidad propia bien definida y que, a pesar de lo que pudiera parecer, se compadece con sus principios. Más bien se trata de dejar constancia de una realidad de largo aliento en el mundo musulmán y muy rica en la diversidad de sus manifestaciones, aun cuando de manera general coincida con la superación de todas las barreras usuales entre el individuo y el Absoluto, pues como ya decía William James:

En los estados místicos nos hacemos uno con el Absoluto y nos damos cuenta de nuestra unidad; y ésta es la tradición mística triunfante y eterna, que apenas se altera por las diferencias de clima y de credo. En el hinduismo, en el neoplatonismo, en el sufismo, en el misticismo cristiano encontramos la misma nota recurrente, de manera que sobre las manifestaciones místicas existe una unanimidad eterna que debería hacer pensar y reflexionar, y que ocasiona que los místicos clásicos no tengan, tal como se ha dicho, una fecha de nacimiento ni una tierra natal. Hablando perpetuamente de la unidad del hombre con Dios, su discurso antecede a cualquier lenguaje y no envejece.

Como ocurre en la mayor parte de las manifestaciones humanas, la Historia suele recoger las acciones llevadas a cabo por varones. Así ocurre también en el ámbito de lo religioso y en el desarrollo de la espiritualidad. Los nombres de personalidades como al-Hallay, Ibn `Arabi, Hafez o Mevlana, son conocidos, así como su producción literaria, sus acciones emblemáticas, su martirio o el hecho de que sirvieran de inspiración para una socialización de la vida espiritual mística, como es el caso de las diversas cofradías que existen y han existido en el mundo sufí

En este sentido, es digno de mención el hecho de la influencia de Mevlana, ligada al origen de los derviches giróvagos y la extensión que alcanzó en el mundo turco, así como en los territorios balcánicos. Como lo es igualmente el caso del andalusí Ibn `Arabi, quien por su parte provee de las pautas para formas posteriores de misticismo y también para el desarrollo de la Teología musulmana, así como para el desarrollo de posturas contrarias a esa Teología, por parte de los tradicionistas más apegados al poder político de muy diversas épocas.

Sin embargo, es de señalar que estas figuras masculinas han tenido precedentes femeninos, compañeras de experiencia mística o incluso maestras de espiritualidad.

5. William James, Las variedades de la experiencia religiosa, $3^{\text {a }}$ ed., ed. Península, Barcelona, 1999 , p. 314.

6. A. Popovic y G. Veinstein, Las sendas de Allah. Las cofradías musulmanas desde sus orígenes hasta la actualidad, ed. Bellaterra, Barcelona, 1997; Emilio Galindo, La experiencia del fuego, ed. Darek Niumba, Madrid, 2002.

Feminismo/s 20, diciembre 2012, pp. 259-273 
La espiritualidad femenina en el mundo musulmán ha poseído y posee una vida subterránea, que aflora de manera indirecta en diversas dimensiones. Tal como ocurre en múltiples culturas, las mujeres, cuya presencia en el espacio público es limitada y, en algunos casos, invisible, sin embargo, son las depositarias de tradiciones, prácticas y creencias que sostienen todo el entramado cultural y perpetúan modos y formas que, de no encontrarse en sus manos, posiblemente habrían desaparecido.

Muchas veces, el elemento femenino es el que transmite de manera oral una visión del mundo y de la vida interior que escapa a los márgenes de lo establecido. Del mismo modo que los cuentos de abuelas y madres ${ }^{7}$ perpetúan las aspiraciones femeninas de una mayor libertad y participación, al tiempo que preservan la intimidad del hogar, de igual manera, ellas son las depositarias de hábitos y costumbres que van desde la confección de especialidades culinarias ligadas a determinadas celebraciones religiosas, a modos de comportamiento, cuyos orígenes con frecuencia ignorados, sin embargo, se hunden en tradiciones que se sustentan en un código ético que tiene su razón de ser en la vivencia religiosa.

En el nacimiento del islam, en particular en la vida del profeta Muhammad, son varias las mujeres que tienen un valor incontestado e incontestable, no sólo en su relación con el propio Profeta, sino en la transmisión de la tradición. Figuras como las muy conocidas de Jadiya, la primera esposa, su hija Fatima o una de sus últimas esposas, Aysha, son depositarias de tradiciones que han permitido la discriminación de cuestiones como la pureza ritual, los modos de la oración o las actividades a emprender antes de cualquier acción para situarse en la presencia divina. Ellas han sido modelo de creyente no sólo para las demás mujeres, sino para los varones.

La tradición del profeta Muhammad (Hadiz) ${ }^{8}$ recoge muchas enseñanzas de este transmitidas por la última de sus esposas. Estas anécdotas nos proveen del retrato de las inquietudes espirituales del Profeta y de muchas de sus actitudes tanto en aspectos rituales como en otros de carácter sapiencial y ético.

Estas mujeres de la historia concreta de los inicios del islam son, por una parte, herederas de la hermana de Faraón o de la Virgen María ${ }^{9}$, como modelos coránicos de mujeres elegidas por Dios para guiar a los creyentes, mostrando su total sumisión a la voluntad divina y su actuación como instrumentos para

7. M. Rabadán Carrascosa, Cuentos palestinos de tradición oral ¿A dormir o a contar?, ed. Cantarabia, Madrid, 2002.

8. M. Abumalham (coord.), Textos de la tradición religiosa musulmana, ed. Trotta, 2005; El Islam. De religión de los árabes a religión universal, ed. Trotta, Madrid 2007.

9. Véase Corán, trad. De Julio Cortés, ed, Herder, Barcelona, 2005. 
el plan de Dios y, por otra parte, son la fuente en la que se apoyan determinadas prescripciones acerca de lo que es lícito comer, de cómo se ha de vestir, de cómo presentarse a la oración, pues ellas, en su cercanía al Profeta son testigos de primer orden para la imitación del modelo profético, del que consta su devoción y su inspiración divina.

Las narraciones que recogen las tradiciones proféticas ponen, además, de relieve cómo, desde los inicios, la sensibilidad femenina provee de determinados detalles que pasan desapercibidos a los varones.

Esta forma peculiar y femenina de contemplar el mundo y de comprender las finuras de la fe hará que desde muy pronto aparezcan otras figuras femeninas que resultan modélicas en el campo de la ascesis.

El islam, una religión que, como ya se ha dicho, promueve el cumplimiento de las normas como modo de mostrar la sumisión a la voluntad divina, desarrollará una espiritualidad más sensible al alejamiento de las normas religiosas y de las costumbres del mundo, precisamente en la forma practicada por las mujeres, aunque conviene señalar que esta especie de 'provocación' frente al mundo y a las normas establecidas es casi una seña de identidad de todos los místicos musulmanes, sean hombres o mujeres.

La ascesis como forma de espiritualidad está muy ligada a la vida femenina desde los primeros tiempos del islam. Muchas mujeres de vida ascética se convertirán en modelos y maestras de espiritualidad de diversos varones.

Es muy probable, no obstante, que haya existido un número más amplio de mujeres significativas en el terreno de la espiritualidad musulmana cuyos nombres y actitudes no nos hayan llegado. Así, aunque escasos los testimonios, no cabe duda de que son significativos de una vida espiritual encarnada por las mujeres que posee una identidad especial y diferenciada de la práctica de los varones.

En los primeros tiempos del islam, destaca una mujer especial de nombre Rabi a al-Adawiyya o al-Qaysiyya (siglo IX d. C.), cuya ascesis y desasimiento del mundo, así como su intimidad y familiaridad con Dios resultan verdaderamente sorprendentes. Su enamoramiento de Dios, expresado en muchas ocasiones, puede parecer cargado de una cierta ingenuidad y de una pureza de sentimientos que raya en la simpleza: «Se cuenta que una noche vio en sueños a Mahoma, y que este le preguntó: ¿Me amas? Ella respondió: ¡Oh Enviado de Dios! ¿Quién hay que no te ame? Pero mi amor a Dios me posee de tal modo que no hay lugar para otro ${ }^{10}$.

10. Félix $M^{a}$ Pareja, La religiosidad musulmana, ed. BAC, Madrid, 1978, pp. 275 y ss.

Feminismo/s 20, diciembre 2012, pp. 259-273 
Esta mujer que era esclava en Basora, a cuyo estado no se sabe cómo llegó, fue emancipada por su dueño quien, al ver una noche que en la cámara donde dormía estaba la luz encendida, se acercó y vio cómo una lámpara se hallaba suspendida sobre la cabeza de la mujer y la oyó hacer la oración que sigue: «Señor, bien sabes que el deseo de mi corazón es obedecerte y que la luz de mis ojos es servirte. Si pudiera, así lo haría y no cesaría una hora en tu servicio, pero me has hecho sujeta a otro y mucho de mi tiempo se pasa en cumplir sus mandatos» ${ }^{11}$.

Su amo, al oír esto, decidió manumitirla. La mujer, una vez libre, se retiró por un tiempo al desierto. Luego, regresó a Basora y residió allí hasta su muerte, convirtiéndose en consejera, maestra e intercesora de cuantos la visitaban. Se dice que en su casa no había candiles pues, de noche, la estancia se iluminaba con la luz que irradiaba de ella. Muchos hechos milagrosos le son, igualmente, atribuidos.

De ella también se cuenta que fue la primera en enunciar la doctrina del 'puro amor a Dios' y en emplear términos como hubb o mahabba, (amor) que hasta entonces se habían referido a los amores profanos y que otros místicos evitaban para no enfrentarse a los teólogos.

Frente a esta categoría de mujeres simples, pero de una profunda espiritualidad, destacarán otras que pueden ser consideradas verdaderas teólogas, con una gran profundidad de pensamiento equiparable a las complejas elaboraciones de muchos místicos.

De modo que entre las mujeres cuya espiritualidad resulta sorprendente o significativa hallamos modelos muy diferentes que van, desde la mujer simple y sin formación, a la mujer intelectual con gran formación y muy buen conocimiento de la teología o la filosofía.

No hace falta mucha imaginación para sospechar que, siendo las mujeres, salvo en las capas altas de la sociedad y en determinadas circunstancias, poco impulsadas al estudio y a adquirir una formación depurada, el número de mujeres con una vivencia profunda de fe y con una espiritualidad aquilatada, pero carentes de formación y, por lo tanto, cuyo nombre u obra no constan, sea muy elevado.

El gran místico Ibn `Arabi, dedica algunos de los poemas y anécdotas recogidos en su obra al-Turjuman a una mujer, Nizam, quien aparece como la manifestación de la grandeza y la belleza de Dios, que se evidencia en sus criaturas. El místico está enamorado de la mujer, que, por otra parte, comparte su espiritualidad y apego a Dios, pero se dirige a ella con una lírica que no es

11. Félix $\mathrm{M}^{\mathrm{a}}$ Pareja, op.cit., ibidem.

Feminismo/s 20, diciembre 2012, pp. 259-273 
profana en la forma y mística en la interpretación, sino que es puramente mística, aunque emplee una lenguaje profano, porque el poeta considera, como se ha dicho, a la mujer una manifestación de la belleza de Dios.

La intensidad del amor a Dios en Ibn `Arabi es semejante a la de Rabi`a y expresada con igual ardor, aunque con la maestría de un consumado poeta:

Mi corazón acoge cualquier forma:

Prado de las gacelas, refugio para el monje,

Templo para ídolos, Ka' ba del peregrino.

Es tablas de la Torá y libro del Corán

Sigo la religión del amor solamente

A donde sus camellos se encaminan.

Mi sola fe es amor y mi creencia ${ }^{12}$.

Tal como sigue, describe Ibn `Arabi uno de sus encuentros con su amada Nizam:

El maestro tenía una hija virginal, doncella esbelta que cautivaba las miradas, adornaba las reuniones, alegraba a los que a ellas asistían y llenaba de confusión a los que la contemplaban. Se llamaba Nizam (Armonía)... Era sabia en materias religiosas, devota, de vida frugal y ascética,...A ella he dedicado en este libro las más bellas composiciones líricas... Dios proteja al lector de esta colección de poemas de que su pensamiento se precipite a lo que no es propio de espíritus elevados y de las miras sublimes en comunión íntima con los negocios celestiales ${ }^{13}$.

Lo que en sus obras nos narra el místico acerca de su relación con esta mujer, nos pone ante un ejemplar femenino de aquilatada espiritualidad y de gran sensibilidad religiosa. La retrata de tal modo que vemos en ella a una mujer que escapa a las convenciones sociales y a los modos de relación con los varones, aceptados por la sociedad de su momento. Sin contravenirlos de manera declarada, no obstante, se muestra libre y espontánea en su familiaridad con el místico, pues ella misma es libre en el seno de su amor a Dios y en su profunda vida espiritual.

Otro de los encuentros quizá con esta misma joven o con otra se describe por parte del místico de la siguiente manera:

Estaba yo una noche realizando el periplo ritual al santuario de la Kaaba, cuando de repente sentí un deleite causado por aquella situación y un estado que ya me era conocido me hizo estremecer. Yo salí entonces del patio pavimentado para evitar al gentío y me puse a realizarlo fuera caminando sobre la arena. Así se me ocurrieron unos versos que me puse a recitar en voz alta de

12. Vicente Cantarino, Casidas de amor profano y místico. Ibn Zaydun. Ibn Arabi, ed. Porrúa, México, 1988, p. 104.

13. V. Cantarino, op., cit., pp. 98-99.

Feminismo/s 20, diciembre 2012, pp. 259-273 
manera que yo mismo los podía oír y también los hubiera escuchado quien conmigo estuviera de haber habido alguno. Eran los que siguen:

Yo quisiera saber si comprenden qué corazón han poseído. Y que mi corazón supiera

las sendas de montaña que han pasado. ¿Crees que están a salvo? ¿Crees que han perecido?

Los príncipes del amor se confunden en el amor y se extravían.

De repente en mi hombro sentí un golpe dado por una mano más suave que la seda, yo me volví y me encontré ante una doncella griega con el rostro más bello, el hablar más dulce y cortés, de sentido más delicado, de alusiones más finas, de conversación más elegante que yo jamás hubiera visto. Sin duda alguna sobrepasaba a todas las gentes de su tiempo en elegancia, belleza y conocimientos.

Ella me preguntó:

-Señor, ¿cómo era lo que dijiste?

A lo que yo contesté: Yo quisiera saber si comprenden/ qué corazón han poseído.

A lo que replicó:

-iCuán extraño en ti que, poseyendo conocimientos como ningún otro en tu generación, digas cosa semejante! ¿Acaso no se conoce todo lo que se posee? ¿Y acaso se puede justificar la posesión sino tras el conocimiento, cuando el deseo de la inteligencia nos ha informado de su carencia? El camino es la lengua de la verdad, ¿cómo se puede entonces permitir a uno como tú que diga cosa semejante? Di, mi señor, ¿qué dijiste después de eso?

Yo respondí: Y que mi corazón supiera/ las sendas de montaña que han pasado.

A lo que replicó:

Señor mío, el sendero montañoso que hay entre lo más profundo del corazón y la mente es precisamente lo que impide llegar a ese conocimiento. Así, ¿cómo va a desear uno en tu situación lo que sólo se puede obtener tras el conocimiento? El camino es la lengua de la verdad, así pues, ¿cómo se puede permitir a uno como tú que diga cosa semejante? Y ¿qué dijiste, mi señor, después de esto?

Yo contesté: ¿Crees que están a salvo?/ ¿Crees que han perecido?

A lo que ella replicó:

-Ellos ciertamente están a salvo. Pregunta, más bien, sobre ti mismo, pues es necesario que te preguntes si tú estás a salvo o has perecido, mi señor. ¿Y qué dijiste después?

Yo contesté: Los príncipes del amor se confunden/ en el amor y se extravían.

Entonces ella exclamó: 
- ¡Oh maravilla! ¿Cómo le va a quedar al enajenado de amores algo con que sentirse confundido, si la razón del amor es precisamente la universalización que aturde los sentidos, roba las inteligencias, confunde los pensamientos y arrebata al que los siente, junto con todas las demás cosas que se escapan? Así pues, ¿dónde está la confusión y qué le queda con que pueda sentirse confuso? El camino es la lengua de la verdad y la expresión ligera e inexacta es impertinencia en uno como tú.

Yo, entonces le pregunté: Tú, muchacha, ¿cómo te llamas? A lo que contestó: Consuelo. Y yo dije: Esto eres para mí. En aquel instante saludó y se marchó. Más tarde yo llegué a conocerla y entablamos unas relaciones amistosas y llegué a percibir que ella poseía los cuatro niveles del conocimiento místico en un grado que nadie es capaz de describir ${ }^{14}$.

El mismo Ibn `Arabi, además de aludir a estas mujeres excepcionales en belleza y hondura mística, en su Epístola de la Santidad ${ }^{15}$, menciona a dos mujeres; Sol, la Madre de los pobres, y Nunna Fatima, hija de Ibn al-Mutanna. De la primera también da noticia en su obra Futuhat, en donde se refiere a ella con el nombre de Jazmín. De ella señala:

Una de las clases de santos amigos de Dios es la de los gemidores. A ella pertenecen así hombres como mujeres. De estas últimas encontré yo una en Marchena de los Olivos, de las tierras de Al-Andalus. Llamábase Jazmín y era de avanzada edad. Santifica Dios a estos místicos, mediante los gemidos que de sus pechos exhalan, porque se sienten incapaces de alcanzar la perfección espiritual y se lamentan al encontrar en sus corazones que no encuentran lo que creen perdido ${ }^{16}$.

Destaca así mismo de esta mujer santa que había alcanzado la perfecta unión con Dios y dice textualmente: «El temor de Dios y la complacencia en su voluntad eran las dos moradas místicas que la dominaban. Lo cual, por cierto, es, a nuestro juicio, cosa que maravilla, pues lograr ambas moradas al mismo tiempo, casi no se concibe» ${ }^{17}$.

Ibn `Arabi dice que vivió en casa de Nunna Fatima, hija de al-Mutanna, durante dos años como servidor suyo. En sus obras cuenta su trato preferente con ella como discípulo y algunos de los prodigios que alcanzó a presenciar. Transmite igualmente algunas de sus expresiones apasionadas de amor a Dios que le había otorgado control sobre todas las cosas creadas, pero no hacía ella

14. Véase V. Cantarino, op. cit., pp. 124-126.

15. Miguel Asín Palacios, Vidas de santones andaluces, ed. Hiperión, Madrid, 1981, pp. 180 y ss.

16. Asín Palacios, op., cit., p. 180, nota 1.

17. Asín Palacios, op., cit., p. 181.

Feminismo/s 20, diciembre 2012, pp. 259-273 
uso de este don y declaraba: «¡Tú, sólo Tú! ¿Toda otra cosa que no seas Tú, es para mí de mal agüero! ${ }^{18}$.

Tan absorta parecía en su Señor que algunos decían que era tonta, pero ella les replicaba: «iEl necio es el que no conoce a su Señor! ${ }^{19}$.

Así pues, uno de los más grandes místicos del islam, personalidad en la que se apoyan incluso hoy numerosas corrientes místicas musulmanas, que se reclaman seguidoras de su experiencia espiritual, pondera el alto grado de espiritualidad de estas mujeres y las considera sus maestras, afirmando que ellas habían alcanzado en la unión con Dios grados que no todos pueden alcanzar.

A lo largo de los siglos medievales y de manera particular en Al-Andalus aparecen algunas mujeres, la mayoría de ellas poetisas, que parecen haber llevado vidas ejemplares y, en épocas tan tempranas como el siglo XI, llegaron a cumplir con el precepto de la peregrinación. No era frecuente hasta tiempos relativamente cercanos que las mujeres emprendieran tan largo y arriesgado viaje. Este es el caso de Maryam, hija de Abu Ya qub al-Faysuli de Silves.

En otros casos, se trata de mujeres que eran reconocidas por los varones como maestras de retórica y ciencias religiosas, tal como es el caso de Safiyya, hija de Abd-Allah de Málaga a quien un discípulo suyo reconoce virtud semejante a la de la Virgen María, y sabiduría y arte poética, comparable a la de las antiguas poetisas preislámicas ${ }^{20}$.

Desde el siglo XIX, el mundo musulmán viene padeciendo situaciones de profunda convulsión política. En primer lugar, la presencia colonial, seguida de la descolonización, que fragmentó territorios naturales e introdujo sistemas políticos alejados de las formas tradicionales de gobierno, para concluir con intentos de reislamización o de implantación de regímenes más o menos democráticos. Todos estos factores produjeron un vuelco en el desarrollo de la religión, de las sociedades y de las costumbres. La espiritualidad musulmana o al menos los intentos conocidos de una renovación del islam, iniciados por personalidades como Muhammad 'Abduh, acorde con las exigencias de las sociedades contemporáneas, fueron adquiriendo un claro tinte social y político y no tanto lo que es propiamente una renovación espiritual, como es el caso de Sayyid Qutb, el fundador de los hermanos Musulmanes.

De tal manera que, en la mayoría de los lugares, ser musulmán pasó de ser un hábito o la expresión de una experiencia religiosa, a radicalizarse o a rechazarse de tal manera que muchos se proclamaron laicistas militantes,

18. Asín Palacios, op., cit., p. 184.

19. Asín Palacios, op., cit., p. 185.

20. Maria Jesús Rubiera Mata, Poesía femenina hispanoárabe, ed. Castalia, Madrid, 1990 pp. 91 y 93. 
mientras otros convirtieron al islam en una ideología política. En estas situaciones de convulsión, muchos creyentes, hombres y mujeres, se mantuvieron en los modos ritualistas heredados, mientras otros se occidentalizaron en sus modos de pensar y aún sin abandonar el islam, como modo de manifestación cultural, optaron por cesar en la práctica, mientras que otros adoptaron el islam como seña de identidad no sólo religiosa, sino también política y social.

En el momento actual resulta difícil llegar a establecer cuáles sean los grados de espiritualidad musulmana vigentes y qué señas específicas pudieran mostrar, no sólo los varones, sino especialmente las mujeres dentro de ella. Se puede afirmar que prevalece el ritualismo como forma de manifestación de la espiritualidad. Así la práctica de la oración se hace muy evidente al igual que la del ayuno anual, tanto entre los varones como entre las mujeres. Los modos de vestir, por ejemplo, constituyen más una seña de identidad distintiva que propiamente la manifestación de una intensa vida espiritual en muchos casos. Cabe decir, que aquellas personas, hombres o mujeres, que a consecuencia de la emigración se hallan en países de mayorías no-musulmanas, suelen hacer gala de su práctica religiosa. Medir el grado de espiritualidad a través del cumplimiento de los ritos es tarea sumamente difícil, tanto como pueda serlo en otras confesiones religiosas.

No obstante, existe un aspecto significativo que conviene al menos señalar. Las cofradías místicas, carentes de figuras significativas desde hace años, por no decir siglos, han pasado a ser en muchos lugares refugio de la religiosidad popular. Junto a ellas y en ocasiones en confusión con ellas, las prácticas mágicas, el culto a los espíritus, el uso de talismanes y la práctica de rituales especiales forman igualmente parte de las manifestaciones de la religiosidad popular.

Muchas de estas formas de práctica religiosa que consisten en peregrinaciones, promesas, sacrificios de animales o rituales más o menos misteriosos, en los que entran procesos de sanación, expulsión de espíritus, de maldición y otros, son ejecutadas por mujeres. Hay quienes califican estos actos de brujería o de simples supercherías convertidas en un negocio, mientras que otros los consideran pervivencia de formas tradicionales o bien producto de la necesidad de amparo y protección en situaciones de depresión económica o de marginación ${ }^{21}$.

No obstante son muy variados estos fenómenos y cada uno de ellos debería ser tratado de manera individualizada con el fin de poder establecer una

21. Fatima Mernissi, Marruecos a través de sus mujeres, $4^{\text {a }}$ ed. Madrid, ed. Del Oriente y el Mediterráneo, Madrid, 1993; El poder olvidado. Las mujeres ante un islam en cambio, ed. Icaria, Barcelona 2003. 
cierta tipología. Es cierto que la mayoría de estas actividades son desempeñadas por mujeres, pero también las ejercen varones, sobre todo en medios deprimidos y subdesarrollados o marginales, lo que, efectivamente, apuntaría a una práctica religiosa convertida en medio de subsistencia. Así mismo, se señala que muchas de estas prácticas las desempeñan personas de color, al menos en el Norte de África, con lo que es de sospechar un cierto sincretismo o influencia de religiones animistas subsaharianas.

Por otra parte, resulta prácticamente imposible separar estas actividades religiosas de la costumbre tradicional de visitar mausoleos o tumbas de santos, práctica que se halla muy extendida en todo el mundo musulmán y que consiste básicamente en llevar a cabo peticiones especiales, que se canalizan a través de la mediación del santo o llevar ofrendas a modo de reconocimiento por gracias concedidas.

El grado de espiritualidad que subyace a estas manifestaciones, cuando van acompañadas de un cumplimiento de los preceptos establecidos en la religión normativa, es difícil de aprehender, si bien parecería que se trata de prácticas que tienen que ver con una fe profunda, aunque poco elaborada, aunque a estos lugares acuda gente de toda condición y clase social.

A modo de resumen final, se podría decir que frente a épocas de esplendor que abarcan desde los inicios del Islam hasta el siglo XVIII, la mística y la espiritualidad, así como en otros espacios y entre otras confesiones, parecen estar en crisis.

\section{Referencias Bibliográficas}

Abumalham, M. «Monoteísmo musulmán, diálogo y mediación», 'Tlu Revista de Ciencias de las Religiones, vol. 9, 2004, pp. 5-12.

—, (coord.), Textos de la tradición religiosa musulmana, ed. Trotta, 2005

—, El Islam. De religión de los árabes a religión universal, ed. Trotta, Madrid 2007. AnaWATI G.C. y L. Gardet, Mystique musulmane. Aspects et tendences, expériences et techniques, Paris, 1961

ARBERRY, A.J. An Introduction to the History of Sufism, London, 1942

—, Le Soufisme, Paris, 1988.

Asín Palacios, M., Vidas de santones andaluces, ed. Hiperión, Madrid, 1981

CANTARINo, V. sidas de amor profano y místico. Ibn Zaydun. Ibn Arabi, ed. Porrúa, México, 1988

CorÁn, trad. De Julio Cortés, ed, Herder, Barcelona, 2005

GaLindo, E., La experiencia del fuego, ed. Darek Niumba, Madrid, 2002

GIRÓN, L. El Talmud, Ed. Del Orto, Madrid, 2006 
JAmes, W., Las variedades de la experiencia religiosa, $3^{\text {a }}$ ed., ed. Península, Barcelona, 1999

Mernissi, F., Marruecos a través de sus mujeres, $4^{\mathrm{a}}$ ed. Madrid, ed. Del Oriente y el Mediterráneo, Madrid, 1993

- El poder olvidado. Las mujeres ante un islam en cambio, ed. Icaria, Barcelona 2003.

PAREJA, F. Ma ., La religiosidad musulmana, ed. BAC, Madrid, 1978, pp. 275 y ss.

Popovic, A. y G. Veinstein, Las sendas de Allah. Las cofradías musulmanas desde sus orígenes hasta la actualidad, ed. Bellaterra, Barcelona, 1997

Puente, C. DE LA, «La oración», en M. Abumalham, Textos de la religiosidad musulmana, ed. Trotta, Madrid, 2005

Rabadán CARrascosa, M., Cuentos palestinos de tradición oral ¿A dormir o a contar?, ed. Cantarabia, Madrid, 2002.

Rubiera Mata, Ma . J., Poesía femenina hispanoárabe, ed. Castalia, Madrid, 1990. 